\title{
AS NORMAS E REGULAMENTAÇÕES DE PROTEÇÃO À PUBLICIDADE DIRIGIDA AO PÚBLICO INFANTIL NO DIREITO BRA̧SILEIRO: ANÁLISE DO LEADING CASE “É A HORA DO SHREK” (RESP 1.588.56/SP)
}

\author{
Jaqueline Bezerra da Silva*
}

Resumo: As crianças enquanto pessoas em peculiar condição de desenvolvimento são consideradas hipervulneráveis. $\mathrm{O}$ arcabouço de normas jurídicas e regulatórias do direito brasileiro seria suficiente para proteger este público nas relações de consumo? Será apresentado o conceito de publicidade dirigida à criança, igualmente será analisado o arcabouço regulatório-normativo da matéria, observando o Leading Case "É a hora do Shrek" (RESP 1.588.086/SP). A hipótese é de que as regulamentações e normas são insuficientes. Como método tem-se a análise qualitativa, utilizando-se da metodologia de pesquisa documental, bibliográfica, revisão de literatura e análise de caso. Faz-se necessária a revisão do tema pelo Parlamento.

Palavras-chave: Publicidade infantil; direitos fundamentais; hipervulnerabilidade; relações de consumo; publicidade abusiva.

\section{RULES AND REGULATIONS FOR THE PROTECTION OF ADVERTISING DIRECTED TO THE CHILD PUBLIC IN BRAZILIAN LAW: ANALYSIS OF THE LEADING CASE “IT'S TIME FOR SHREK” (RESP 1.588.56 / SP)}

\begin{abstract}
Children as people in a peculiar developmental condition are considered hypervulnerable. Would the framework of legal and regulatory norms of Brazilian law be sufficient to protect this public in consumer relations? The concept of advertising aimed at children will be presented, as well as the regulatory-normative framework of the matter, observing the Leading Case "It's Shrek's time" (RESP 1.588.086/SP). The hypothesis is that regulations and standards are insufficient. As a method there is a qualitative analysis, using the methodology of documentary research, bibliography, literature review and case analysis. It is necessary to review the subject by Parliament.
\end{abstract}

Keywords: Children's advertising; fundamental rights; hypervulnerability; consumer relations; abusive advertising.

\section{Introdução}

\footnotetext{
* Mestranda no Programa de Pós-graduação em Direito da Pontifícia Universidade Católica de Campinas (PUC Campinas), bolsista FAPIC-Reitoria. Integra a linha de pesquisa Direitos Humanos e Políticas Públicas. Membro do grupo de pesquisa Direito e Realidade Social.(CNPq/PUC Campinas). Graduada em Direito pela Pontifícia Universidade Católica de Campinas (2019). Atua desde 2014 em escritório jurídico especializado em Direito do Trabalho. Áreas de interesse: Direitos humanos; Políticas Públicas; Direitos Fundamentais na Primeira Infância e Direito das crianças. E-mail: jaquelinebezerra@icloud.com
} 
O conceito de publicidade para o direito do consumidor pode ser compreendido como a ferramenta que auxilia na publicização gerando a circulação de bens e serviços, contribuindo com a economia e geração de riquezas.

De acordo com os escritos de Bauman, estamos inseridos em uma sociedade de consumidores. Considerando que essa ferramenta auxilia na circulação de bens e serviços, seu papel torna-se fundamental dentro da lógica do consumo.

Por sua vez, a publicidade infantil é a utilização dessa ferramenta dirigida à seres humanos até doze anos, segundo a concepção de criança adotada pela doutrina do Estatuto da Criança e do Adolescente (ECA).

O Código de Defesa do Consumidor (CDC) visa a proteção aos direitos do consumidor, bem como disciplina as responsabilidades entre o fornecedor com o consumidor, estabelecendo padrões de conduta, prazos e penalidades. O CDC disciplina o tema da publicidade, sendo vedadas as publicidades enganosas e abusivas. Uma publicidade será abusiva se: gerar discriminação; provocar violência; explorar medo ou superstição; aproveitar-se da falta de experiência da criança; desrespeitar valores ambientais; induzir a um comportamento prejudicial à saúde e à segurança.

A criança enquanto pessoa em desenvolvimento, deve ser protegida desse tipo de exposição. Assim, a publicidade abusiva direcionada às crianças fere diretamente direitos fundamentais, visto que às violações causadas por essa exposição a publicidade com táticas persuasivas podem acarretar prejuízos relacionadas à saúde nutricional, psicológica e seu bem estar, contrariando, também, diretamente o Objetivo de Desenvolvimento Sustentável (ODS) $\mathrm{n}^{\circ}$ 3, da Agenda 2030 da Organização das Nações Unidas (ONU) que aborda a promoção da saúde e bem estar como essencial ao fomento das capacidades humanas.

A problemática da publicidade direcionada ao público infantil defronta a característica da hipervulnerabilidade intrínseca a essa população. De acordo com a doutrina consumerista: “A hipervulnerabilidade seria a situação social fática e objetiva de agravamento da vulnerabilidade da pessoa física consumidora, por circunstâncias pessoais aparentes ou conhecidas do fornecedor" (Marques; Miragem, 2012, p. 188). 
A Resolução n ${ }^{\circ} 163$ de 2014 do Conselho Nacional da Criança e do Adolescente $^{2}$ (CONANDA) soma-se às leis já existentes para promover a proteção às publicidades voltadas à criança e aos adolescentes e traz a definição de que é abusivo o direcionamento de publicidade e comunicação mercadológica à criança explicitando um rol exemplificativo das estratégias mais utilizadas para esse fim.

O Conselho Nacional de Autorregulamentação Publicitária traz diretrizes específicas para a elaboração de anúncios publicitários para o público infantil em seu Código Brasileiro de Autorregulamentação Publicitária, com intuito de impedir a publicidade abusiva constranja consumidores, tendo como aspecto principal ser uma orientação facultativa, embora a sua inobservância possa acarretar penalidades administrativas aos seus associados.

A Lei ${ }^{\circ}$ 13.257/2016, mais conhecida como Marco Legal pela Primeira Infância, em seu artigo $5^{\circ}$, expõe a necessidade de proteção das crianças na primeira infância contra pressão consumista e exposição à comunicação mercadológica.

Assim, considerando o contexto da hipervulnerabilidade da criança dentro da lógica consumerista, somado à preocupação do legislador em promover a proteção delas, justifica-se a pertinência do presente artigo.

A relação de consumo, nesse caso, é entre particulares: consumidor por equiparação (criança) e fornecedores. Entretanto, devido à ausência de capacidade processual dos infantes e discernimento reduzido para que compreendam que seus direitos foram lesados, dificilmente seus responsáveis ingressarão no Poder Judiciário para discutir violações de seus direitos fundamentais. Nestes casos, órgãos de defesa do consumidor como o Procon, ou Organizações que atuam em defesa dos direitos das crianças, como o Instituto Alana, oferecem as denúncias de possíveis ilegalidades ao Ministério Público.

Assim, torna-se imperioso que os fornecedores sejam responsáveis e acatem a legislação vigente nas relações consumeristas, em especial em relação às técnicas de publicidade dirigidas aos produtos e serviços destinados ao público infantil.

\footnotetext{
${ }^{2}$ O Conanda é um órgão vinculado à Secretaria Especial de Direitos Humanos da Presidência da República, composto por representantes de entidades da sociedade civil e de ministérios do Governo Federal. Seus conselheiros atuam na formulação e controle das políticas públicas para a infância e a adolescência, fiscalizando o cumprimento e a aplicação das normas do ECA.
} 
Em setembro de 2020, foi realizada revisão de literatura a fim de se verificar o estado da arte, nas bases de dados Scielo e BTDT, utilizando-se dos descritores combinados publicidade infantil e direitos fundamentais em ambas as plataformas. Dos 209 resultados provenientes de ambas as plataformas, foram selecionados 23 trabalhos pertinentes ao tema.

Foi identificado que os principais problemas decorrentes da publicidade infantil são: consumismo, obesidade e sobrepeso, erotização precoce e formação de valores materialistas.

A maior parte dos resultados advindos da revisão de literatura eram da área da saúde, nutrição, medicina e psicologia. Na maior parte dos casos, as preocupações com a obesidade infantil motivaram os trabalhos. Apenas um resultado era de conteúdo das ciências jurídicas, embora, muitos autores desenvolvam suas fundamentações e conclusões com base na melhora de políticas públicas ou regulamentação/proibição da publicidade infantil. Considerando que a temática da infância tem qualidade multidisciplinar, faz-se necessária a expansão dos estudos sobre essa população, corroborando para a justificativa do trabalho.

Nesse sentido, o presente trabalho pretende verificar se a normas jurídicas e a regulamentação atual são suficientes para a proteção dos direitos fundamentais das crianças face às ferramentas publicitárias destinadas ao público infantil baseando-se em fundamentação jurídica dos Ministros do Superior Tribunal de Justiça na decisão do leading case, "É a hora do Shrek" (RESP 1.588.086/SP). Para nortear o presente trabalho a questão proposta é: O arcabouço normativo e regulatório referente a publicidade infantil atual é suficiente para a proteção dos direitos fundamentais das crianças?

A hipótese é de que a legislação e regulamentação já existentes referentes aos direitos da criança são suficientes para a proteção dos seus direitos fundamentais face frente aos desafios da publicidade dirigida à criança, entretanto, a não observância por parte das empresas privadas é pautada em interesses econômicos e, sobretudo, devido à ausência de sanções coercitivas e inibitórias no contexto da autorregulamentação.

Como objetivos gerais, pretende-se compreender o conceito de publicidade infantil e a condição de hipervulnerável das crianças nas relações consumeristas e identificar quais são os impactos negativos decorrentes dessa prática. Em relação aos objetivos específicos, analisar o arcabouço regulatório e normativo para identificar se ele é suficiente para a proteção dos 
direitos fundamentais das crianças face à publicidade dirigida a este público, bem como verificar a argumentação jurídica protetiva aos direitos da criança utilizada no leading case "É a hora do Shrek!”, RESP 1.558.086 SP.

O método qualitativo foi eleito para o presente estudo, será utilizada a pesquisa bibliográfica, documental e estudo de caso.

\section{PUBLICIDADE INFANTIL}

A publicidade é um termo inerente à sociedade de consumo (Bauman, 2008), e está presente diariamente no cotidiano, seja em meio físico ou digital. O carro de som que anuncia as promoções no centro da cidade, o outdoor na avenida, o anúncio que antecede a visualização do vídeo no Youtube ou surge durante a navegação em tantas outras plataformas. De acordo com Rabaça e Barbosa (1978, p. 378) o conceito de publicidade pode ser compreendido como "qualquer forma de divulgação de produtos ou serviços, através de anúncios geralmente pagos e veiculados sob a responsabilidade de um anunciante identificado, com objetivos de interesse comercial".

O que diferencia a publicidade comum da publicidade infantil é o direcionamento do apelo ao consumo a um público-alvo específico, nesse caso, as crianças de até doze anos completos $^{3}$. Esse direcionamento de publicidade ou segmentação de mercado é utilizado para identificar consumidores com características comuns - necessidades, desejos, hábitos de consumo, e objetiva a otimização de estratégias mercadológicas de comunicação ${ }^{4}$ e criação de marketing $^{5}$. De acordo com Kotler; Ketler (2012), observando as principais variáveis da segmentação para mercados consumidores dos Estados Unidos da América existem cerca de 25 bases de segmentação: região geográfica, tamanho da família, idade, geração, classe social, raça, etc.

\footnotetext{
${ }^{3}$ Art. $2^{\circ}$ Considera-se criança, para os efeitos desta Lei, a pessoa até doze anos de idade incompletos, e adolescente aquela entre doze e dezoito anos de idade. (Brasil, 1990, Art. $2^{\circ}$ )

${ }^{4}$ A comunicação mercadológica, é aquela projetada para ser persuasiva para conseguir o efeito calculado nas atitudes e ou no comportamento do público visado, faz-se pela venda pessoal, promoção de vendas, merchandising, relações públicas, embalagem, marketing direto, propaganda e publicidade.

(Pinho, 2001, p.40) -

${ }^{5} \mathrm{O}$ marketing envolve a identificação e a satisfação das necessidades humanas e sociais. Uma das mais sucintas e melhores definições de marketing é a de "suprir necessidades gerando lucro". (Kotler, Keller 2012, p. 3)
} 
As estratégias utilizadas nas análises de marketing que chegam ao consumidor pelas vias da publicidade são extremamente apuradas, sobretudo se observarmos a utilização dos smartphones às nossas vidas de forma habitual somada a quantidade de dados relevantes que fornecemos voluntariamente - ou não ${ }^{6}$ - aos aplicativos, seja pela geolocalização, aceite de cookies durante a navegação, dentre outros exemplos. Nessa lógica, (Castro, 2012) compreende que a chamada interpelação algorítmica $^{7}$ do consumidor desencadeou o fenômeno da nichificação, estreitando os perfis em nichos direcionados para o consumo.

Partindo dessa perspectiva de segmentação e nichificação, o direcionamento da publicidade está cada vez mais refinado e persuasivo. Pensando no público-alvo adulto, esse direcionamento específico teria suas nuances entre os benefícios e malefícios, porém, com o público-alvo infantil essa premissa pode se tornar incorreta em virtude da persuasão destinada a uma parcela da população que não possui completa compreensão da realidade.

Os impactos negativos da publicidade dirigida às crianças são fundados, especialmente, na limitada capacidade de discernimento inerente a idade, sendo que a essa imaturidade natural decorrente de seu estágio de desenvolvimento é protegida constitucionalmente pela doutrina da proteção integral, conforme o artigo 227, da Constituição Federal de $1988^{8}$.

Embora a doutrina da proteção integral esteja inserida na Constituição Federal desde 1988, a mudança fática na sociedade vem ocorrendo lentamente, mas já logrou êxitos se compararmos as publicidades veiculadas na década de 1990 e dos anos $2000^{9}$ que exploravam

\footnotetext{
${ }^{6}$ The Great Hack é um documentário de 2019 sobre o escândalo de dados do Facebook-Cambridge Analytica, produzido e dirigido por Jehane Noujaim e Karim Amer, ambos os documentários indicados ao Oscar. A música do filme foi composta pelo compositor indicado ao Emmy Gil Talmi. Disponível na plataforma de streaming Netflix.

7 A interpelação algorítmica do consumidor caracteriza-se pela mensurabilidade, submetendo atributos, atividades e interações a diversos tipos de métricas; pela recursividade, refinando-se continuamente com base em informações sobre si fornecidas de alguma forma pelo próprio consumidor; pelo perfilamento, definindo perfis a partir da articulação contingente de traços obtidos de cada um; pela nichificação, agrupando perfis afins em nichos direcionados ao consumo; e pela ubiquidade, operando através de diversos meios e dispositivos. Serão analisados também os efeitos da interpelação algorítmica do consumidor em termos de estratégias retóricas da publicidade e de estratégias de controle social. (Castro, 2018, p. 1)

${ }^{8}$ É dever da família, da sociedade e do Estado assegurar à criança, ao adolescente e ao jovem, com absoluta prioridade, o direito à vida, à saúde, à alimentação, à educação, ao lazer, à profissionalização, à cultura, à dignidade, ao respeito, à liberdade e à convivência familiar e comunitária, além de colocá-los a salvo de toda forma de negligência, discriminação, exploração, violência, crueldade e opressão. (Redação da EC 65/2010) (BRASIL, 1988, Art. 227).

${ }^{9}$ Ver os seguintes exemplos: https://www.youtube.com/watch?v=5lrtBh1xeQ8
} 
temáticas sexistas que fomentavam a adultização e erotização precoce, por exemplo. De acordo com Zannete (2017) as principais problemáticas relacionadas a lesão de direitos das crianças em se tratando de publicidade infantil seriam ligadas a mudança de comportamento.

Ainda, transtornos alimentares e obesidade, consumismo, erotização precoce, estresse familiar e violência/delinquência poderiam ser impactos desencadeados a partir da publicidade direcionada ao público infantil, conforme estudo realizado pelo Instituto Alana em 2014.

As problemáticas citadas importam em violações de direitos fundamentais das crianças pelas vias da publicidade dirigida ao público infantil. Esse público-alvo é caracterizado por mais uma agravante, a condição de hipervulnerabilidade, isto, pois, a ausência de maturidade física e mental intensifica a vulnerabilidade já típica dos consumidores, conforme a doutrina consumerista. A hipervulnerabilidade como característica inerente ao processo de desenvolvimento psicobiológico social da criança será explorada a seguir.

\title{
1.1 Hipervulnerabilidade das crianças face à publicidade infantil
}

O direito do consumidor prevê proteção para as partes mais vulneráveis da relação de consumo (Art $4^{\circ}, \mathrm{I}, \mathrm{CDC}$ ). Presumidamente, os consumidores pessoas físicas, bem como as pessoas em situação de vulnerabilidade, seja de ordem técnica, fática, informacional ou jurídica, chamada de vulnerabilidade geral. A doutrina e jurisprudência identificaram um agravamento de ordem fática que caracteriza a chamada hipervulnerabilidade ou vulnerabilidade agravada:

\begin{abstract}
A hipervulnerabilidade seria a situação social fática e objetiva de agravamento da vulnerabilidade da pessoa física consumidora, por circunstâncias pessoais aparentes ou conhecidas do fornecedor, como sua idade reduzida (assim, o caso da comida para bebês ou da publicidade para crianças) [...]. (Marques; Miragem, 2012, p .188).
\end{abstract}

A hipervulnerabilidade tem o seu reconhecimento como um grupo diferenciado de consumidores que em virtude de suas diferentes necessidades ou relevância (crianças, idosos, gestantes, pessoas com deficiência) merecem tutela diferenciada nas de relação de consumo: "[...] foi identificada mais recentemente uma nova categoria de pessoas que se 
encontram na condição de hipervulneráveis, ou seja, aqueles cuja fragilidade se apresenta em maior grau de relevância ou de forma agravada." (Bolzan, 2014, p. 156, grifo nosso).

A fragilidade da criança está justamente no seu processo de desenvolvimento cognitivo incompleto, sendo que as técnicas persuasivas utilizadas nas estratégias publicitárias são incompatíveis com o próprio nível de discernimento desse público, caracterizando, portanto, a descrita hipervulnerabilidade. O caderno legislativo que analisou os projetos de lei sobre a publicidade infantil do projeto Criança e Consumo do Instituto Alana ressalta "a capacidade manipuladora da comunicação mercadológica, que conscientemente se aproveita da falta de julgamento e experiência da criança. (Alana, 2014, p. 20, grifo nosso)

Considerando a condição peculiar de pessoa em desenvolvimento das crianças, somado ao fato de as chamadas técnicas persuasivas serem capazes de manipular a mente humana, é notória a fragilidade e a necessidade de proteção extraordinária nas relações consumeristas que envolvam o público infantil.

De toda sorte, o já citado artigo 227 da Constituição Federal estabelece a doutrina da proteção integral à criança, bem como outras disposições normativas e regulatórias que salvaguardam a exposição dessa população à publicidade abusiva. Nesse sentido, a seguinte pergunta é proposta: $\mathrm{O}$ arcabouço regulatório e normativo brasileiro que dispõe os regulamentos e normas relativas à publicidade dirigida ao público infantil é suficiente para que os direitos fundamentais dessa população não sejam violados?

O próximo capítulo se aterá a análise da legislação e regulamentação aplicável protetiva aos direitos da criança observando o contexto da publicidade infantil, bem como as regulamentações específicas do Conselho Nacional de Autorregulamentação publicitária (CONAR) e do Conselho Nacional dos Direitos da Criança e do Adolescente (CONANDA), com destaque para a publicidade abusiva de alimentos em atenção ao leading case "É a hora do Shrek” (RESP 1.588.086/SP). que será analisado no último capítulo.

\section{ARCABOUÇO REGULATÓRIO E NORMATIVO JURÍDICO SOBRE A PUBLICIDADE INFANTIL NO DIREITO BRASILEIRO}

As normas jurídicas 
De início, é importante observar que a positivação dos direitos da criança no ordenamento jurídico interno se deu em virtude de um movimento gradativo de direitos internacionais humanos das crianças ocorrido no século $\mathrm{XX}$, notadamente a Convenção Internacional Sobre os Direitos da Criança (CDC) de 1989, incorporada no direito interno brasileiro pelo Decreto Executivo n 99.710 de 1990 representa o tratado de maior relevância sobre a proteção e promoção dos direitos das crianças.

A Convenção Internacional Sobre os Direitos da Criança é o mais bem aceito da história, os Estados-Partes se conscientizam novamente da condição peculiar de pessoa em desenvolvimento das crianças, reiterando o Princípio II que trata do direito das crianças à especial proteção para o desenvolvimento físico e social previsto na Declaração Universal dos Direitos da Criança (1959).

O Princípio do Melhor Interesse da Criança é disposto neste tratado, bem como, posteriormente, encontra correspondência no Estatuto da Criança e do Adolescente.

Ainda, no item 2 do artigo $3^{\circ}$ da referida convenção, há previsão expressa sobre o compromisso dos Estados-Partes em assegurar à criança a proteção e o cuidado necessário para o seu bem-estar, tendo em vista os direitos e deveres de suas figuras parentais ou responsáveis legais, tomando as medidas legislativas e administrativas adequadas para esse fim. $\mathrm{O}$ item 3 do mesmo artigo também dispõe a obrigação dos Estados-partes em certificar que as instituições, serviços e estabelecimentos que são responsáveis pelo cuidado e proteção das crianças cumpram os padrões determinados pelas autoridades competentes, observando sobretudo à segurança e à saúde das crianças. No caso do Brasil, podemos vislumbrar, a título de exemplo, a figura do Parquet representada nesse artigo, sendo o Ministério Público o organismo responsável pela tutela de interesses difusos e coletivos das crianças.

Além disso, os Estados-Partes também devem proteger as crianças de todas as formas de exploração que possam prejudicar qualquer aspecto de seu bem-estar, assim como reconhecem o direito a um nível devidamente adequado ao seu desenvolvimento físico, mental, espiritual, moral e social.

Se referindo diretamente a comunicação mercadológica a Convenção dispõe sobre a temática nos artigos 17 in verbis: 
Os Estados-parte reconhecem a importante função exercida pelos meios de comunicação de massa e assegurarão que a criança tenha acesso às informações e dados de diversas fontes nacionais e internacionais, especialmente os voltados à promoção de seu bem-estar social, espiritual e moral e saúde física e mental.

Com essas expressas previsões, tem-se que a exposição das crianças às diversas modalidades de publicidade deve ter como objetivo o seu pleno desenvolvimento físico, mental e psicológico. Ocorre que em muitos casos da exposição das crianças às diversas modalidades de publicidade há violações de direitos em virtude das ferramentas persuasivas utilizadas que podem impactar diretamente no seu pleno desenvolvimento e bem-estar.

Com a explicitação dos artigos da Convenção Internacional Sobre os Direitos da Criança pertinentes à temática do presente estudo, parte-se para a análise do direito doméstico voltado à proteção da criança consumidora.

Os referidos documentos internacionais de direitos humanos que antecederam a Constituição Federal de 1988 somado às reuniões que possibilitaram a elaboração da Convenção Internacional Sobre os Direitos da Criança foram fundamentais para a positivação da doutrina da proteção integral no artigo 227 , demonstrando uma efetiva transformação no pensamento a sociedade:

É dever da família, da sociedade e do Estado assegurar à criança, ao adolescente e ao jovem, com absoluta prioridade, o direito à vida, à saúde, à alimentação, à educação, ao lazer, à profissionalização, à cultura, à dignidade, ao respeito, à liberdade e à convivência familiar e comunitária, além de colocá-los a salvo de toda forma de negligência, discriminação, exploração, violência, crueldade e opressão. (Redação dada Pela Emenda Constitucional nº 65, de 2010) (Brasil, 1988, Art. 227).

Os direitos fundamentais narrados no caput do artigo citado permitem que a criança se desenvolva plenamente, vinculando o dever de assegurar esses direitos não somente à família, o dever de proteção integral foi estendido à sociedade e ao Estado, por opção legislativa. A proteção aos consumidores também é um direito constitucional, de modo que a defesa dos direitos do consumidor enquanto criança encontra dupla correspondência protetiva no texto da magna carta, seja no artigo 227 ou no artigo $5^{\circ}$, inciso XXXII:

Todos são iguais perante a lei, sem distinção de qualquer natureza, garantindo-se aos brasileiros e aos estrangeiros residentes no País a inviolabilidade do direito à vida, à liberdade, à igualdade, à segurança e à propriedade, nos termos seguintes:

XXXII - o Estado promoverá, na forma da lei, a defesa do consumidor; (Brasil, 1988, Art. $5^{\circ}$, XXXII) 
Nas disposições constitucionais que trata a ordem econômica a previsão expressa da devida observância ao princípio da defesa do consumidor é reiterada na lei maior, artigo 170, inciso V: "A ordem econômica, fundada na valorização do trabalho humano e na livre iniciativa, tem por fim assegurar a todos existência digna, conforme os ditames da justiça social, observados os seguintes princípios: V - defesa do consumidor".

A tutela dos direitos do consumidor e a proteção integral da criança são inequívocas no texto da Constituição Federal. A criança, em virtude de sua condição peculiar de pessoa em desenvolvimento, necessita de atenção especial por parte de toda a sociedade para que progrida em sua plenitude. De outro lado, a proteção ao consumidor é necessária dentro da sociedade de consumo, considerando que no atual grau de desenvolvimento da nossa sociedade é mais fácil produzir os bens ou serviços do que vendê-los. Assim, as estratégias de marketing frequentemente consubstanciadas nas diversas roupagens das publicidades persuasivas criam falsas necessidades para que os consumidores sintam o desejo de consumir, simplesmente, por consumir. Essa situação de fragilidade em virtude das estratégias de marketing somada a vulnerabilidade inerente ao consumidor seja ela de ordem técnica, fática, informacional ou jurídica dá guarida à necessária proteção constitucional.

Dando continuidade às normas protetivas do direito doméstico, o Estatuto da Criança e do Adolescente ${ }^{10}$ (ECA), em seu artigo $4^{\circ}$ confirma a disposição trazida no artigo 227 da Constituição de que é um dever compartilhado assegurar com absoluta prioridade a efetivação dos direitos fundamentais da criança.

$\mathrm{O}$ artigo $5^{\circ}$ do ECA prevê a proteção dos direitos fundamentais das crianças, in verbis: "Nenhuma criança ou adolescente será objeto de qualquer forma de negligência, discriminação, exploração, violência, crueldade e opressão, punido na forma da lei qualquer atentado, por ação ou omissão, aos seus direitos fundamentais.” O artigo $3^{\circ}$ do mesmo diploma também dispõe que toda criança goza de todos os direitos fundamentais inerentes à pessoa humana, sem prejuízo da proteção integral de que trata a lei, assegurando-se lhes o devido desenvolvimento físico, mental, moral, espiritual e social.

\footnotetext{
${ }^{10}$ É o conjunto de normas do ordenamento jurídico brasileiro que tem como objetivo a proteção integral da criança e do adolescente.
} 
Devido à responsabilidade de proteção integral compartilhada, as empresas privadas deverão observar cautelosamente os direitos fundamentais dos pequenos consumidores durante o desenvolvimento, criação e veiculação de suas estratégias mercadológicas. Sendo que seja na hipótese de ação ou omissão haverá a punição se caracterizada a violação, desde que haja denúncia às entidades competentes.

Partindo para análise do Código de Defesa do Consumidor, os direitos básicos do consumidor previstos no artigo $6^{\circ}$ do $\mathrm{CDC}$ tratam de valores fundamentais para que as relações entre fornecedor e consumidor possam ocorrer com dignidade (Senacon, 2014). Os direitos à vida, saúde e segurança são também preceitos fundamentais que devem ser estritamente observados pelos fornecedores que destinem seus produtos e serviços aos consumidores de até doze anos. De acordo com estudo do Instituto Alana (2014) a publicidade dirigida ao público infantil pode causar danos ao desenvolvimento infantil saudável, sendo que a obesidade, os transtornos alimentares, o alcoolismo e a diminuição das brincadeiras criativas, consumismo, violência, a erotização precoce, os transtornos de comportamento são considerados violações aos referidos direitos.

A proteção contra a publicidade enganosa e abusiva também foi prevista pelo legislador como um direito básico, artigo $6^{\circ}$, IV, CDC. O próprio Código de Defesa do Consumidor disciplina a proibição dessas modalidades, bem como as define em um rol exemplificativo em seu artigo 37, considerando abusiva a publicidade que se aproveite da deficiência de julgamento e experiência da criança, reforçando a teoria da proteção integral prevista constitucionalmente.

Nesse sentido, as empresas além de acatar o dever constitucional de assegurar a proteção integral à criança e aos seus direitos fundamentais, devem observar as disposições trazidas no Estatuto da Criança e do Adolescente que reiteram essa teoria, igualmente devem respeitar as regras referentes às relações consumeristas nas práticas comerciais com esse público.

O artigo $5^{\circ}$ da Lei 13.257/2016 conhecida como Marco Legal da Primeira Infância define como áreas prioritárias para as políticas públicas da primeira infância a proteção da criança contra a pressão consumista, bem como a adoção de medidas que evitem a exposição precoce à comunicação mercadológica. 
No que diz respeito ao Conselho Nacional dos Direitos da Criança e do Adolescente, no uso de suas atribuições, dispôs a Resolução nº 163 de 2014 para tratar especificamente sobre a abusividade do direcionamento da publicidade e de comunicação mercadológica à criança e ao adolescente.

A resolução pacífica a questão terminológica ligada a publicidade e comunicação mercadológica, sendo esta última um gênero de atividades ligadas à comunicação comercial para divulgação de produtos, serviços, marcas e empresas independentemente do suporte, da mídia ou do meio utilizado, da qual a publicidade é uma espécie. Dispondo as principais modalidades de comunicação mercadológica: anúncios impressos, comerciais televisivos, spots de rádio, banners e páginas na internet, embalagens, promoções, merchandising, ações por meio de shows e apresentações e disposição dos produtos nos pontos de venda.

É considerada prática abusiva o direcionamento de publicidade e comunicação mercadológica que tenha intenção de persuadir a criança para o consumo de qualquer produto ou serviço, utilizando as ferramentas do rol exemplificativo tais como linguagem infantil, efeitos especiais e excesso de cores, trilhas sonoras de músicas infantis ou cantadas por vozes de criança, bonecos ou similares, promoção com distribuição de prêmios ou de brindes colecionáveis ou com apelos ao público infantil dentre outros.

Desde os documentos internacionais, passando pela Constituição Federal, Estatuto da Criança e do Adolescente, Código de Defesa do Consumidor, Marco Legal da Primeira Infância até a Regulamentação n 163/2014 do Conanda há a constatação de normas jurídicas de proteção aos direitos da criança e do consumidor no ordenamento jurídico brasileiro, contudo, em nenhuma delas há menção a sanções específicas na hipótese de descumprimento.

\subsection{A autorregulamentação publicitária}

O Conselho Nacional de Autorregulamentação Publicitária (CONAR) é responsável pela autorregulamentação da publicidade no Brasil, composto por entidades anunciantes, agências de publicidade e empresas de comunicação. As ações do Conselho são pautadas no Código Brasileiro de Autorregulamentação Publicitária (CBAP).

No artigo primeiro do preâmbulo do CBAP há a previsão de que todos os anúncios devem respeitar e conformar-se às leis do país. Nos Princípios Gerais, da Seção 11, no artigo 
37 está disposta regulamentação específica para as ações de produtos e serviços destinados às crianças e jovens. Há previsão nas alíneas do inciso I do referido artigo de um rol de práticas que os anunciantes deverão se abster relativas ao tema, por exemplo: associar crianças e adolescentes a situações incompatíveis com sua condição, sejam elas ilegais, perigosas ou socialmente condenáveis; provocar constrangimento aos pais ou responsáveis; impingir consumo; empregar crianças e adolescentes como modelos para vocalizar apelo direto, recomendação ou sugestão de uso ou consumo. ${ }^{11}$

O inciso II define que os produtos destinados ao consumo por crianças e adolescentes deverão em seus anúncios contribuir para o desenvolvimento positivo das relações familiares, escolares e demais relacionamentos que envolvam esse público. Ainda deverão respeitar a dignidade, ingenuidade, credulidade, inexperiência e o sentimento de lealdade do públicoalvo. Deverão dar atenção especial às características psicológicas das crianças, presumida o seu incompleto desenvolvimento de discernimento e abster-se de estimular comportamentos socialmente condenáveis.

O Código define que não será permitida publicidade ou merchandising que empregue crianças, elementos do universo infantil ou outros artifícios com a deliberada finalidade de captar a atenção desse público específico, qualquer que seja o veículo utilizado, bem como em relação aos produtos segmentados para o público infantil a publicidade exclusiva para esse público somente poderá ocorrer de forma restrita aos intervalos e espaços comerciais.

As crianças não figurarão como modelos publicitários em anúncios que promovam bens ou serviços incompatíveis com a condição desse público, como as armas de fogo, bebidas alcoólicas, cigarros, loterias, e todos os demais restritos em virtude de lei.

O Anexo H da Seção II referente às categorias especiais de anúncio do CBAP trata de alimentos, refrigerantes, sucos e bebidas assemelhadas e será analisado brevemente em atenção ao leading case "É a hora do Shrek" (RESP 1.588.086/SP) de que tratará o último capítulo deste estudo.

\footnotetext{
${ }^{11}$ Recomendável acessar o Código Brasileiro de Autorregulamentação Publicitária na íntegra: http://www.conar.org.br/codigo/codigo.php
} 
Nos anúncios relativos aos produtos citados é recomendado aos anunciantes abster-se de desmerecer o papel dos pais, educadores e profissionais de saúde. Há previsão para a possível utilização de personagens do universo infantil ou apresentadores de programas dirigidos a este público nos intervalos comerciais. A priori, essa previsão seria conflitante com o artigo $2^{\circ}$, V da resolução 163/2014 do Conanda que considera abusiva a comunicação mercadológica que utilize personagens ou apresentadores infantis para persuadir o público ao consumo de qualquer bem ou serviço. É indicado abster-se de utilizar crianças muito acima ou muito abaixo do peso, segundo padrões biométricos comumente aceitos, para evitar que possam atingir a sua dignidade. Também é indicada abstenção a estímulos imperativos de compra ou consumo quando o produto for destinado à criança, com exceção para campanhas educativas que promovam hábitos alimentares saudáveis.

Conforme o exposto, embora haja uma extensa recomendação para os cuidados da publicidade que seja afeta ao público infantil pelo Código Brasileiro de Autorregulamentação Publicitária do CONAR, a principal problemática envolvida na autorregulamentação é a ausência de coercibilidade de tais disposições. Em regra, na hipótese de violações de direitos fundamentais por inobservância do próprio CBAP ou de lei, órgãos de defesa do consumidor como o Procon ou organizações que atuam nos interesses dos direitos das crianças são os responsáveis por denunciar tais práticas ao CONAR ou ao Ministério Público para que sejam tomadas levadas a cabo possíveis sanções e, posteriormente, algumas disputas serão discutidas no Poder Judiciário.

Portanto, embora haja normas e regulamentações que disciplinem a proteção das crianças frente às publicidades abusivas, tem-se que a ausência de previsões específicas de sanção no texto da lei são o principal desafio para que os direitos sejam protegidos e a principal causa para a violação, pois, nem sempre haverá sanção administrativa no Conar ou estas violações serão levadas a discussão no Poder Judiciário.

\section{3 “É A HORA DO SHREK" (RESP 1.588.086/SP)}

O último capítulo desse estudo visa identificar os argumentos utilizados no Leading Case "É a hora do Shrek" (RESP 1.588.086/SP) para buscar compreender se as normas e regulamentações relativas à publicidade infantil são suficientes para protegê-las de possíveis violações aos seus direitos fundamentais nos casos de publicidade dirigida ao público infantil. 
Contextualizando o caso, em 2007 a Bauducco foi denunciada pelo Programa Criança e Consumo do Instituto Alana ao Ministério Público do Estado de São Paulo (MPSP) após verificar a publicidade infantil e venda casa de alimento com brinquedo na campanha publicitária: “A hora do Shrek ${ }^{12}$ ”. Era necessário juntar 5 (cinco) embalagens dos produtos (bolo ou biscoito) mais $\mathrm{R} \$ 5,00$ (cinco reais) para adquirir o relógio colecionável do personagem Shrek, criado exclusivamente para essa finalidade.

A Bauducco foi condenada no Superior Tribunal de Justiça em 2016 por publicidade duplamente abusiva, primeiramente por direcionamento da publicidade ao público infantil, em segundo lugar por tratar-se de evidente venda casada:

\begin{abstract}
A hipótese dos autos caracteriza publicidade duplamente abusiva. Primeiro, por se tratar de anúncio ou promoção de venda de alimentos direcionada, direta ou indiretamente, às crianças. Segundo, pela evidente "venda casada", ilícita em negócio jurídico entre adultos e, com maior razão, em contexto de marketing que utiliza ou manipula o universo lúdico infantil (art. 39, I, do CDC). 3. In casu, está configurada a venda casada, uma vez que, para adquirir/comprar o relógio, seria necessário que o consumidor comprasse também 5 (cinco) produtos da linha "Gulosos". Recurso especial improvido. (BRASIL, Superior Tribunal de Justiça. REsp n ${ }^{\circ}$ 1.558-086-SP, Rel. Min. Humberto Martins, Diário da Justiça Eletrônico, Brasília, 10 mar. 2016)
\end{abstract}

Em 2017 o Supremo Tribunal Federal manteve a condenação proferida pelo Superior Tribunal de Justiça.

Posteriormente, o processo relativo ao requerimento de anulação da multa efetuada pelo PROCON foi retomado e julgado improcedente no ano de 2019 pelo Tribunal de Justiça do Estado de São Paulo.

Conforme explicitado pelo Relator Ministro Humberto Martins, a publicidade de venda de alimentos dirigida direta ou indiretamente às crianças é considerada abusiva. A ilegalidade reside, sobretudo, em campanhas publicitárias que utilizem ou manipulem o universo lúdico e infantil, como ocorreu no presente caso, subsumindo sua fala ao artigo 37, $\S 2^{\circ}$, do CDC.

O nobre relator não traz em sua decisão elementos de proteção à criança exteriores ao Código de Defesa do Consumidor, visto que esse diploma já dispõe regra específica para a publicidade direcionada às crianças, adequando-se perfeitamente ao caso concreto.

\footnotetext{
${ }^{12}$ Campanha Publicitária "É a hora do Shrek" https://www.youtube.com/watch?v=pROsWr3avg8
} 
O Ministro Humberto Martins exalta a participação do Instituto Alana, e do Ministério Público Estadual exortando a opinião do Subprocurador-Geral da República:

Daí surge a correta, e oportuna, participação do INSTITUTO ALANA, e do Ministério Público Estadual, em defesa dos direitos das crianças, buscando preservar, in casu, os valores que lhes são repassados por meio da comercialização dos produtos da recorrente, bem como dos reflexos causados na formação do caráter desses menores por ocasião da venda desses produtos. (BRASIL, Superior Tribunal de Justiça. REsp n¹.558-086-SP, Rel. Min. Humberto Martins, Diário da Justiça Eletrônico, Brasília, 10 mar. 2016, grifo nosso.)

A manifestação do Ministro Herman Benjamin acompanha a decisão do eminente relator, bem como reforça a decisão do voto exemplar advindo da origem de que no presente caso trata-se de publicidade duplamente abusiva, em virtude do direcionamento da publicidade às crianças no que tange a produtos alimentícios, somada à venda casada. Continua seus argumentos no sentido de que a decisão sobre a dieta dos filhos cabe somente aos pais:

[...] E aqui, ao contrário do que foi dito da Tribuna, não se trata de paternalismo sufocante nem de moralismo demais, é o contrário, significa reconhecer que a autoridade para decidir sobre a dieta dos filhos, é dos pais. E que nenhuma empresa comercial, e nem mesmo outras que não tenham interesse comercial direto, têm o direito constitucional legal assegurado de tolher a autoridade e o bom senso dos pais. (BRASIL, Superior Tribunal de Justiça. REsp n ${ }^{\circ} .558-086-S P$, Rel. Min. Herman Benjamin. Diário da Justiça Eletrônico, Brasília, 10 mar. 2016)

O argumento está em perfeita consonância com o artigo 227 da Constituição Federal em relação ao dever compartilhado de assegurar à criança com absoluta prioridade os direitos fundamentais, nesse caso, em especial o direito à saúde e à alimentação.

Em sua intelecção, o Ministro Herman afirma que no que diz respeito ao sistema de regulação de publicidade do Código de Defesa do Consumidor não é necessário o resultado da infração, bastaria a prática da conduta em si mesma para a caracterização da infração. Nesse entendimento, a opção por criar e veicular publicidade direcionada à criança aproveitando de seu discernimento incompleto são suficientes para o enquadramento em publicidade abusiva, passível de sanção. Afirma também que embora a criança não tenha consentimento jurídico capaz de completar o negócio jurídico, tem o poder de convencimento para com os pais, familiares e responsáveis.

A Ministra Assusete Magalhães também acompanhou o voto do relator, mencionando os artigos referentes às práticas abusivas do Código de Defesa do Consumidor, e em suas 
considerações ponderou que a publicidade abusiva é ainda mais grave em virtude de a criança ter o discernimento incompleto, mas que tem grande capacidade de convencimento sobre seus pais, responsáveis ou familiares para aquisição daqueles produtos que lhe interessam.

Conforme os argumentos trazidos pelos julgadores, percebe-se que apenas as normas jurídicas do Código de Defesa do Consumidor foram colocadas expressamente nos exercícios interpretativos de cada um deles, embora a manifestação do Ministro Herman Benjamin seja a mais dotada de argumentos baseados em questões morais e ainda que de modo não expresso, há a perspectiva da doutrina integral em sua fala, in verbis:

\begin{abstract}
Então repito não se trata de moralismo demasiado, de paternalismo sufocante, aliás, estes foram os argumentos utilizados para questionar até o Supremo Tribunal Federal a vedação da publicidade de tabaco, os mesmos argumentos. De que se havia liberdade absoluta, de que na verdade a publicidade de tabaco não era para estimular as pessoas a fumarem, era para escolher uma marca em relação à outra, todos estes argumentos são iguaizinhos, e é bom que a indústria alimentícia que é tão importante e tão séria, aliás, eu sou consumidor da Bauducco, aqui é um consumidor falando, acho que outros aqui também, apreciamos estes produtos. Mas é bom que a indústria alimentícia tenha esta percepção de que estes são argumentos batidos, que foram rejeitados em outro contexto, evidentemente que num contexto muito mais sério, da publicidade de tabaco. Também não me impressiona, ainda neste primeiro ponto, um outro argumento de que milhares de anúncios são feitos, são mesmo, e por isso a necessidade de o Superior Tribunal de Justiça dizer, não apenas para a Bauducco, mas para toda a indústria alimentícia, ponto final, acabou. (BRASIL, Superior Tribunal de Justiça. REsp n ${ }^{\circ} 1.558-086-\mathrm{SP}$, Rel. Min. Herman Benjamin, Diário da Justiça Eletrônico, Brasília, 10 mar. 2016)
\end{abstract}

Com a análise dos argumentos jurídicos trazidos nesse leading case, é perceptível que os julgadores do Superior Tribunal de Justiça adotam uma posição positivista, apenas subsumindo o caso concreto às normas de defesa do consumidor, sem trazer reflexões expressas sobre a doutrina da proteção integral, explicitando o dever compartilhado das empresas privadas em não violar os direitos fundamentais das crianças, por exemplo.

\title{
Considerações Finais
}

O sistema de normas protetivas aos direitos da criança face à publicidade dirigida a criança no ordenamento jurídico brasileiro é extremamente rico. Percorrendo as disposições dos tratados internacionais de que o Brasil é signatário, a Constituição Federal com previsão da doutrina da proteção integral no emblemático artigo 227, o Estatuto da Criança e do Adolescente que emerge essa população como sujeitos de direitos, as próprias disposições específicas do Código de Defesa do Consumidor para a proteção das crianças, a Resolução 
n $163 / 2014$ do Conselho Nacional dos Direitos da Criança e do Adolescente, o Marco Legal da Primeira Infância e até mesmo as disposições não vinculantes do Código Brasileiro de Autorregulamentação Publicitária demonstram que a sociedade brasileira tem se preocupado com a dignidade da infância.

Todas as normas jurídicas e regulamentos sobre os direitos da criança elencadas nos documentos acima narrados são adequadas para a proteção integral dos direitos fundamentais da criança face à publicidade dirigida ao público infantil, entretanto, a ausência de disposição de sanções na hipótese de violação de direitos das crianças é o principal problema para a ausência de efetividade desse sistema, representando, portanto, uma insuficiência.

Outro ponto relevante, diz respeito a tímida atuação do Ministério Público, órgão responsável pela tutela de interesses difusos e coletivos das crianças. De acordo com a pesquisa Publicidade Infantil no Conar elaborada pela Associação Brasileira de Publicidade, no período compreendido entre setembro de 2006 a agosto de 2013, foram analisadas 276 campanhas publicitárias dirigidas às crianças que foram julgadas pelo Conar. Apenas 8 campanhas foram denunciadas pelo Ministério Público, o que corresponde a apenas 3\% do total de denúncias.

O consumidor foi responsável por $50 \%$ das denúncias, seguidamente do Conar $41 \%$ e o Instituto Alana 11\%. Com esses números é patente que a atuação do Ministério Público no que diz respeito a reprimir às publicidades abusivas ao público infantil é insuficiente, deixando ao consumidor, dentro da perspectiva de autorregulação, a mercê dos abusos cometidos pelas agências de publicidade e anunciantes.

Dessa forma, a atuação do Ministério Público precisa ser fomentada para que haja um firme combate às práticas da publicidade abusiva no contexto da infância no Brasil, a fim de que os direitos fundamentais das crianças sejam devidamente preservados e não apenas reparados.

Embora o contexto da autorregulamentação seja extremamente sensível a críticas, é de bom tom observar que os esforços do Conar trouxeram significativos impactos na diminuição da publicidade infantil se compararmos o que ocorria nas décadas de 1990 e 2000 . A indústria 
das agências de publicidade tem observado o contexto da publicidade infantil, sendo possível encontrar várias cartilhas de recomendação para essa temática em seus websites, por exemplo.

Essa mudança no comportamento das agências é um reflexo do próprio comportamento da sociedade que é cada vez mais consciente da importância da infância no contexto do desenvolvimento humano. A promulgação da Constituição Federal, a ratificação e incorporação da Convenção Internacional Sobre os Direitos da Criança, a instituição do ECA no ordenamento jurídico brasileiro já galgou avanços na proteção integral dos direitos da criança, porém é necessário que o Poder Público, observando o Marco Legal da Primeira Infância, avance em medidas mais efetivas para que haja a real proteção integral da criança estabelecida pelo constituinte originário.

Caminhando nesse sentido, em recente decisão, o Poder Judiciário, em sua máxima representação - o plenário do Supremo Tribunal Federal (STF), por unanimidade, julgou constitucional a Lei $n^{\circ}$ 13.582/2016 do Estado da Bahia, alterada pela Lei $n^{\circ} 14.014 / 2018$, que versa sobre a proibição da publicidade dirigida ao público infantil em ambientes escolares.

A lei referente ao ano de 2016, foi questionada pela Associação de Emissoras de Rádio e Televisão (ABERT), na Ação Direta de Inconstitucionalidade de nº 5631.

Diante da questão, o STF em sua composição plena julgou, por unanimidade, a improcedente a ADI 5631 alegando ser constitucional a legislação estadual proibir comunicação mercadológica dirigida à criança em ambiente escolar do ensino básico.

De toda sorte, o caso analisado trouxe um novo paradigma para decisões ligadas à publicidade dirigida ao público infantil, representando um marco histórico na proteção integral dos direitos fundamentais das crianças, porque reflete a mudança social em julgado de grande relevo. É certo que a decisão foi extremamente acertada para proporcionar a efetiva proteção à publicidade infantil na realidade do caso. Entretanto, a ausência de explicitação de argumentos jurídicos referentes à proteção integral da criança torna a construção sólida dessa doutrina um desafio até para o Poder Judiciário.

É entendido que em razão do dever compartilhado de assegurar absoluta prioridade aos direitos fundamentais das crianças, é necessário que as normas relativas às violações 
sejam revistas pelo Poder Legislativo, assim como feito pelo Estado da Bahia a fim de que se tornem mais eficazes contra os abusos cometidos contra essa população hipervulnerável.

\section{Referências}

ASSOCIAÇÃO BRASILEIRA DE AGÊNCIAS DE PUBLICIDADE. Associação Brasileira de Agências de Publicidade. Publicidade Infantil no Conar. São Paulo: Abap, 2013. 28 p. Disponível em: < http://www.abapnacional.com.br/pdfs/publicacoes/publicidade-infantil-conar.pdf > . Acesso em: 03 dez. 2020.

ASSEMBLEIA GERAL DAS NAÇÕES UNIDAS (ONU). Convenção das Nações Unidas sobre os Direitos da Criança. 1989. Disponível em: <http://www.planalto.gov.br/ccivil_03/decreto/19901994/d99710.htm>. Acesso em: 12 set. 2020.

BAUMAN, Zygmunt. Vida para consumo: a transformação das pessoas em mercadoria. Rio de Janeiro: Jorge Zahar Editora, 2008.

BOLZAN, Fabrício. Direito do consumidor esquematizado. 2a edição. São Paulo: Saraiva, 2014. BRASIL. Código de Defesa do Consumidor - Lei n . 8.078/1990. Brasília, Disponível em: < http://www.planalto.gov.br/ccivil_03/leis/18078compilado.htm>. Acesso em: 12 set. 2020. BRASIL. Constituição da República Federativa do Brasil de 1988. Brasília, Disponível em: < http://www.planalto.gov.br/ccivil_03/constituicao/constituicao.htm>. Acesso em: 13 set. 2020. BRASIL. Resolução n.163 do Conselho Nacional dos Direitos da Criança e do Adolescente (CONANDA), de 13 de março de 2014. Dispõe sobre a abusividade do direcionamento de publicidade e de comunicação mercadológica à criança e ao adolescente. Diário Oficial da União. Brasília, 04 abr. 2014. Disponível em: <https://www.legisweb.com.br/legislacao/?id=268725>. Acesso em: 11 nov. 2020.

BRASIL. Estatuto da Criança e do Adolescente - Lei no . 8.069/90. Brasília, Disponível em: < http://www.planalto.gov.br/ccivil_03/leis/18069.htm>. Acesso em: 13 nov. 2020.

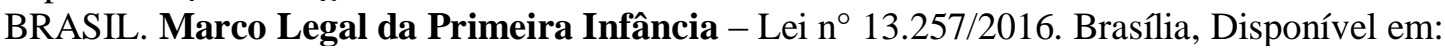
http://www.planalto.gov.br/ccivil_03/_ato2015-2018/2016/lei/113257.htm. Acesso em: 22 nov. 2020. BRASIL. Superior Tribunal de Justiça. Recurso Especial no 1.558.086/SP (2015/0061578-0), $2^{\text {a }}$ Turma, Rel. Min. Humberto Martins, julgado. 10 mar. 2016, Diário da Justiça Eletrônico, Brasília, 15 abr. 2016. Disponível em: < https://bdjur.stj.jus.br/jspui/bitstream/2011/113808/Julgado_1.pdf> Acesso em: 23 de nov. 2020

BRASÍLIA. SUPREMO TRIBUNAL FEDERAL. Lei da Bahia que proíbe propaganda em estabelecimentos de educação básica é constitucional: por unanimidade, o plenário entendeu que a norma estadual pode impor restrições visando proteger a saúde de crianças e adolescentes.. Por unanimidade, o Plenário entendeu que a norma estadual pode impor restrições visando proteger a saúde de crianças e adolescentes.. 2021. Disponível em:

http://portal.stf.jus.br/noticias/verNoticiaDetalhe.asp?idConteudo=463023\&ori=1. Acesso em: 10 abr. 2021.

BRASÍLIA. Leonardo Roscoe Bessa. Secretaria Nacional do Consumidor. Manual de Direito do Consumidor. 4. ed. Brasília: Escola Nacional de Defesa do Consumidor, 2014. 293 p. Disponível em: $\langle$ https://www.defesadoconsumidor.gov.br/images/manuais/manual-do-direito-do-consumidor.pdf $>$. Acesso em: 20 nov. 2020.

CASTRO, Julio Cesar Lemes de. O consumo na era da interpelação algorítmica. Intercom -

Sociedade Brasileira de Estudos Interdisciplinares da Comunicação, Sorocaba, p. 1-15, set. 2018. Disponível em: https://portalintercom.org.br/anais/nacional2018/resumos/R13-1148-1.pdf. Acesso em: 01 dez. 2020.

CONAR. Código Brasileiro de Autorregulamentação Publicitária. São Paulo. Conselho Nacional de Auto Regulamentação Publicitária, 1980. Disponível em:

<http://www.conar.org.br/codigo/codigo.php>. Acesso em: 11 nov. 2020. 
CRIANÇA E CONSUMO. Iniciativa Alana. ADI 5631 - Lei no 13.582 de 2016 do estado da Bahia (dezembro/2016). 2021. Disponível em: https://criancaeconsumo.org.br/acoes/adi-5631-lei-no-13582-de-2016-do-estado-da-bahia-dezembro2016/. Acesso em: 10 abr. 2021.

ESTADO DA BAHIA Assembleia Legislativa. Lei Ordinária nº 14.045, de 27 de dezembro de 2018. Altera a Lei $n^{\circ}$ 13.582/2016, para dispor sobre a publicidade infantil nos estabelecimentos de educação básica no Estado da Bahia. Salvador, BA, Disponível em:

http://www.legislabahia.ba.gov.br/documentos/lei-no-14045-de-27-de-dezembro-de-2018. Acesso em: 10 abr. 2021.

ESTADO DA BAHIA. Assembleia Legislativa. Lei Ordinária no 13.582, de 14 de setembro de 2016. Regulamenta a publicidade infantil de alimentos no Estado da Bahia. Salvador, BA, Disponível em: http://www.legislabahia.ba.gov.br/documentos/lei-no-13582-de-14-de-setembro-de-2016. Acesso em: 10 abr. 2021.

INFORMATIVO STF. Brasília: Supremo Tribunal Federal, Secretaria de Altos Estudos, Pesquisas e Gestão da Informação, n. 1011/2021. Disponível em:

http://portal.stf.jus.br/textos/verTexto.asp?servico=informativoSTF. Data de divulgação: 9 de abril de 2021.

JUNIOR, Vidal Serrano. Constituição Federal: Avanços, contribuições e modificações no processo democrático brasileiro. Coordenação Ives Gandra Martins e Francisco Rezek. São Paulo: Editora Revista dos Tribunais: CEI - Centro de Extensão Universitária, 2008. Páginas 845-846.

KOTLER, P., \& KELLER, K. (2012). Administração de Marketing. Tradução Sônia Midori Yamamoto; revisão técnica Edson Crescitelli. - 14. ed. - São Paulo: Pearson Education do Brasil, 2012.

MARQUES, Cláudia Lima; MIRAGEM, Bruno. O novo direito privado e a proteção dos vulneráveis. São Paulo: Revista dos Tribunais, 2012.

ORGANIZAÇÃO DAS NAÇÕES UNIDAS. Assembleia Geral das Nações Unidas. Convenção das Nações Unidas sobre os Direitos da Criança. 1989. Disponível em <

http://www.planalto.gov.br/ccivil_03/decreto/1990-1994/d99710.htm>. Acesso em: 18 nov. 2020

ORGANIZAÇÃO DAS NAÇÕES UNIDAS. Assembleia Geral das Nações Unidas. Declaração

Universal dos Direitos da Criança. 1959. Disponível em:

http://www.dhnet.org.br/direitos/sip/onu/c_a/lex41.htm Acesso em 18 de nov. 2020.

ORGANIZAÇÃO DAS NAÇÕES UNIDAS. Assembleia Geral das Nações Unidas. Declaração

Universal dos Direitos Humanos. 1948. Disponível em <:

http://www.direitoshumanos.usp.br/index.php/Declara\%C3\%A7\%C3\%A3o-Universal-dos-Direitos-

Humanos/declaracao-universal-dos-direitos-humanos.html>. Acesso em 18 de nov. 2020

ORGANIZAÇÃO DAS NAÇÕES UNIDAS. Objetivos de Desenvolvimento Sustentável: Assegurar uma vida saudável e promover o bem-estar para todos, em todas as idades. 2020. Objetivo 3.

Disponível em: https://odsbrasil.gov.br/objetivo/objetivo?n=3. Acesso em: 26 nov. 2020.

PINHO, José Benedito. Comunicação em Marketing. São Paulo: Papirus, 9. ed. 2001.

PROJETO CRIANÇA E CONSUMO. Por que a publicidade faz mal para as crianças. 2. ed. São

Paulo: Instituto Alana, 2009, p.1-69. Disponível em: < https://criancaeconsumo.org.br/biblioteca/porque-a-publicidade-faz-mal-para-as-criancas/>. Acesso em: 24 out. 2020.

PROJETO CRIANÇA E CONSUMO. A Constitucionalidade da Resolução 163 do Conselho

Nacional dos Direitos da Criança (Conanda). Parecer do Professor Bruno Miragem. São Paulo: Instituto Alana, 2014, p.1-47. Disponível

em: $<$ https://criancaeconsumo.org.br/wpcontent/uploads/2014/02/Parecer_ProfBrunoMiragem.pdf $>$.

Acesso em: 24 out. 2020.

PROJETO CRIANÇA E CONSUMO. A Constitucionalidade da Restrição da Publicidade de Alimentos e de Bebidas Não Alcoólicas voltada ao Público Infantil. Parecer emitido pelo Professor Virgílio Afonso da Silva. São Paulo: Instituto Alana, 2012, p.1-31. Disponível em: < https://criancaeconsumo.org.br/biblioteca/parecer-professor-virgilio-afonso-da-silva-a-

constitucionalidade-da-restricao-da-publicidade-de-alimentos-e-de-bebidas-nao-alcoolicas-voltada-aopublico-infantil/>. Acesso em: 24 out. 2020.

Revista de Dir., Globalização e Responsabilidade nas Relações de Consumo | e-ISSN: 2526-0030 |

Encontro Virtual | v. 7 | n. 1 | p. 111 - 133 | Jan/Jul. 2021. 
RABAÇA, Carlos Alberto; BARBOSA, Gustavo. Dicionário de comunicação. Rio de Janeiro: Codecri, 1978.

ZANETTE, Sandra Muriel Zadróski. A PROTEÇ̃̃o INTEGRAL DA CRIANÇA E O

CONTROLE DA PUBLICIDADE INFANTIL NA SOCIEDADE DE CONSUMO. 2017. $339 \mathrm{f}$.

Dissertação (Mestrado) - Curso de Direito, Programa de Pós Graduação em Direito, Universidade Federal de Santa Catarina, Florianópolis, 2017. Disponível em:

$<$ https://repositorio.ufsc.br/xmlui/bitstream/handle/123456789/176801/346341.pdf?sequence=1\&isAll owed=y>. Acesso em: 24 out. 2020. 